\title{
Ecosystem responses to internal and watershed organic matter loading: consequences for hypoxia in the eutrophying Neuse River Estuary, North Carolina, USA
}

\author{
Hans W. Paerl*, James L. Pinckney, John M. Fear, Benjamin L. Peierls \\ Institute of Marine Sciences, University of North Carolina at Chapel Hill, 3431 Arendell Street, Morehead City,
} North Carolina 28557, USA

\begin{abstract}
The contrasting impacts of externally supplied (runoff) and internally generated (nutrientstimulated phytoplankton blooms) organic matter on oxygen $\left(\mathrm{O}_{2}\right)$ depletion were examined and evaluated in the eutrophic, salinity-stratified Neuse River Estuary, North Carolina, USA. This nitrogen (N)limited estuary is experiencing increasing anthropogenic $\mathrm{N}$ loading from expanding urban, agricultural and industrial development in its watershed. Resultant algal blooms, which provided organic matter loads capable of causing extensive low $\mathrm{O}_{2}$ (hypoxic) and depleted $\mathrm{O}_{2}$ (anoxic) conditions, have induced widespread mortality of resident fin- and shellfish. Phytoplankton blooms followed periods of elevated $\mathrm{N}$ loading, except during extremely high runoff periods (e.g. hurricanes), when high rates of flushing and reduced water residence times did not allow sufficient time for bloom development. During these periods, hypoxia and anoxia were dominated by watershed-derived organic matter loading. Externally vs internally generated organic matter loading scenarios were examined in sequential years (1994 to 1996) to compare the differential impacts of an average discharge year (10 yr mean hydrological conditions) (1994), N-stimulated summer algal blooms (1995), and a major hurricane (Fran; September 1996). The responses of primary production, hypoxia, and anoxia to these hydrologically contrasting years and resultant organic matter loadings help distinguish watershed from internal forcing of $\mathrm{O}_{2}$ dynamics and fish kills.
\end{abstract}

KEY WORDS: Estuarine eutrophication - Anoxia - Hypoxia - Fish kills - Organic matter - Nitrogen . Hurricanes

\section{INTRODUCTION}

Estuaries are highly productive habitats, providing ecologically and economically valuable fin- and shellfish refugia, nurseries (Steele 1974), and dynamic nutrient transformation zones at the interface between freshwater and marine environments (Nixon 1986, 1995). Intense biogeochemical processing enables estuaries to filter watershed-derived natural and anthropogenic nutrients and toxic substances (Kennedy 1986), minimizing potential detrimental effects on coastal and oceanic water quality and fisheries resources (Neilson \& Cronin 1981, Dyer \& Orth 1994, Cloern 1996).

-E-mail: hans_paerl@unc.edu
The protective buffering role of estuaries comes with an ecological price, however. Horizontal and vertical salinity gradients driven by freshwater discharge promote density stratification and the formation of salt wedges (Pritchard 1955, Geyer 1988). Strong, persistent density gradients hamper mixing and oxygen exchange with the atmosphere and overlying oxic waters. When accompanied by warm temperatures and high levels of organic matter (OM) input, stratification isolates bottom waters and associated decomposing $\mathrm{OM}$, leading to rapid and at times extensive bottom-water dissolved oxygen $\left(\mathrm{O}_{2}\right)$ depletion (Malone et al. 1988, Cooper \& Brush 1991, Parker \& O'Reilly 1991, Welsh \& Eller 1991). OM inputs can be derived from nutrient-driven internal water column and benthic primary production or external watershed sources. 
Bottom-water $\mathrm{O}_{2}$ depletion resulting from $\mathrm{OM}$ loading events can cause hypoxia $\left(<4 \mathrm{mg} \mathrm{O}_{2} \mathrm{I}^{-1}\right.$; North Carolina Department of Environment, Health and Natural Resources, Division of Water Quality, standard) or anoxia (total $\mathrm{O}_{2}$ depletion). Hypoxia is physiologically stressful for fish, shellfish, and invertebrates and prolonged (hours to days) exposure to anoxia is fatal to most endemic fauna (Van Dolah \& Anderson 1991, Winn \& Knott 1992). The duration, frequency, and spatial distribution of OM-driven $\mathrm{O}_{2}$ depletion are key indicators of ecosystem metabolism and health. Characterizations of $\mathrm{O}_{2}$ dynamics have been used to assess anthropogenic impacts on water quality and biogeochemical (nutrient cycling) changes in estuarine and coastal waters worldwide (Elmgren 1989, Ambio 1990. De Jonge et al. 1994, Justic et al. 1996).

Increasing trends in estuarine hypoxia/anoxia have been linked to nutrient (specifically nitrogen) enhanced primary production, eutrophication, and increased OM loading from growing and evolving watershed use (Ambio 1990, Cooper \& Brush 1991, De Jonge et al. 1994). Conversion of forests to agricultural and urban landscapes, river flow diversions, water control structures, and increasing wastewater discharges are common examples of watershed disturbances (Elmgren 1989, Dyer \& Orth 1994). Natural versus manmade controls of bottom-water hypoxia and anoxia are difficult to establish, however, because few estuaries are entirely free of anthropogenic nutrient loading. In estuaries receiving accelerating urban, agricultural, and industrial discharges, assessments of the relative roles of these controlling factors is a contentious and challenging scientific and management issue for watershed land use, environmental, and socioeconomic planning.

The Neuse River Estuary, USA, which drains one of North Carolina's most productive and rapidly growing urban, industrial, and agricultural watersheds, is currently classified eutrophic to hypertrophic (300 to $>400$ $\mathrm{gC} \mathrm{m}^{-2} \mathrm{yr}^{-1}$ ) according to Nixon's (1995) trophic state index. Like most temperate estuaries, primary production is controlled by rates of nitrogen ( $N$ ) supply (Ryther \& Dunstan 1971, D'Elia et al. 1986, Granéli et al. 1990, Paerl et al. 1990a, b, Rudek et al. 1991, Fisher et al. 1992), which in the case of the Neuse River are dominated by non-point sources ( $75 \%$ of annual $\mathrm{N}$ load) (Harned \& Davenport 1990, Dodd et al. 1993). The total $N$ load has increased by at least $30 \%$ over the past 2 decades (Stanley 1988, Harned \& Davenport 1990, Dodd et al. 1993). Within this time frame, the Neuse River Estuary has experienced increased symptoms of water quality degradation. Nuisance dinoflagellate and cyanobacterial blooms have proliferated (Hobbie \& Smith 1975, Tedder et al. 1980, Paerl 1983. 1987. Christian et al. 1986, Paerl et al. 1995), and it is suspected that hypoxia- and anoxia-associated fish kills have likewise increased, giving the Neuse River the dubious distinction of being one of the 20 most threatened rivers in the U.S. (American Rivers Foundation 1997). Rapidly growing and diversifying non-point and point sources of $\mathrm{N}$ (e.g. agricultural expansion, urban wastewater and residential use of $\mathrm{N}$ fertilizers, proliferating intensive animal operations) are implicated as the primary cause for these troubling symptoms of eutrophication (Copeland \& Hart 1995).

We had the opportunity to examine hypoxia and anoxia dynamics during 3 successive, but hydrologically contrasting, years (1994 to 1996). This enabled us to evaluate and compare the impacts of nutrient-driven phytoplankton blooms versus OM-enriched runoff associated with a major hurricane (Fran; 5 September 1996) on hypoxia, anoxia, and reported fish kills in the estuary.

\section{MATERIALS AND METHODS}

A biweekly sampling program was initiated along a $42 \mathrm{~km}$ transect spanning freshwater, oligohaline, and mesohaline segments of the Neuse River Estuary in early 1994. Sampling consisted of vertical profiles of physical, chemical, and irradiance conditions in the water column at 6 fixed locations in the Neuse River, which was expanded to 8 locations in May 1996 (Fig. 1). Water was collected at the surface and $0.5 \mathrm{~m}$ above the bottom and transported to the Institute of Marine Sciences (IMS) for determining phytoplankton primary productivity, and chlorophyll a (chl a), particulate $\mathrm{CHN}$ and dissolved organic $\mathrm{C}$ concentrations. Measurements of dissolved inorganic nitrogen (DIN; nitrate, nitrite, ammonium) and dissolved inorganic phosphorus (DIP; orthophosphate) were made to assess nutrient availability and to construct nutrient input budgets for different river segments.

Primary productivity was determined using the ${ }^{14} \mathrm{C}$ method, adapted for in situ estuarine conditions by Paerl (1987). Triplicate light and single dark $125 \mathrm{ml}$ Pyrex reagent bottles were filled with Neuse River Estuary water from locations indicated in Fig. 1, followed by the addition of $0.3 \mathrm{ml}$ of ${ }^{14} \mathrm{C}-\mathrm{NaHCO}_{3}\left(7.5 \mu \mathrm{Ci} \mathrm{ml}{ }^{-1}\right.$, $58 \mathrm{mCi} \mathrm{mmol}^{-1}$; ICN Pharmaceuticals Inc.). Incubations were conducted in the IMS outdoor pond system for 3 to $4 \mathrm{~h}$ during midday under natural light and temperature conditions, using a light field simulator, mimicking variable light regimes experienced in the Neuse River Estuary water column (Mallin \& Paerl 1992). After incubation, 50 to $125 \mathrm{ml}$ sub-samples (depending on particulate matter content) were filtered at 200 torr vacuum through $25 \mathrm{~mm}$ Whatman GF/F glass fiber filters. Filters were then fumed in a $\mathrm{HCl}$-saturated atmos- 


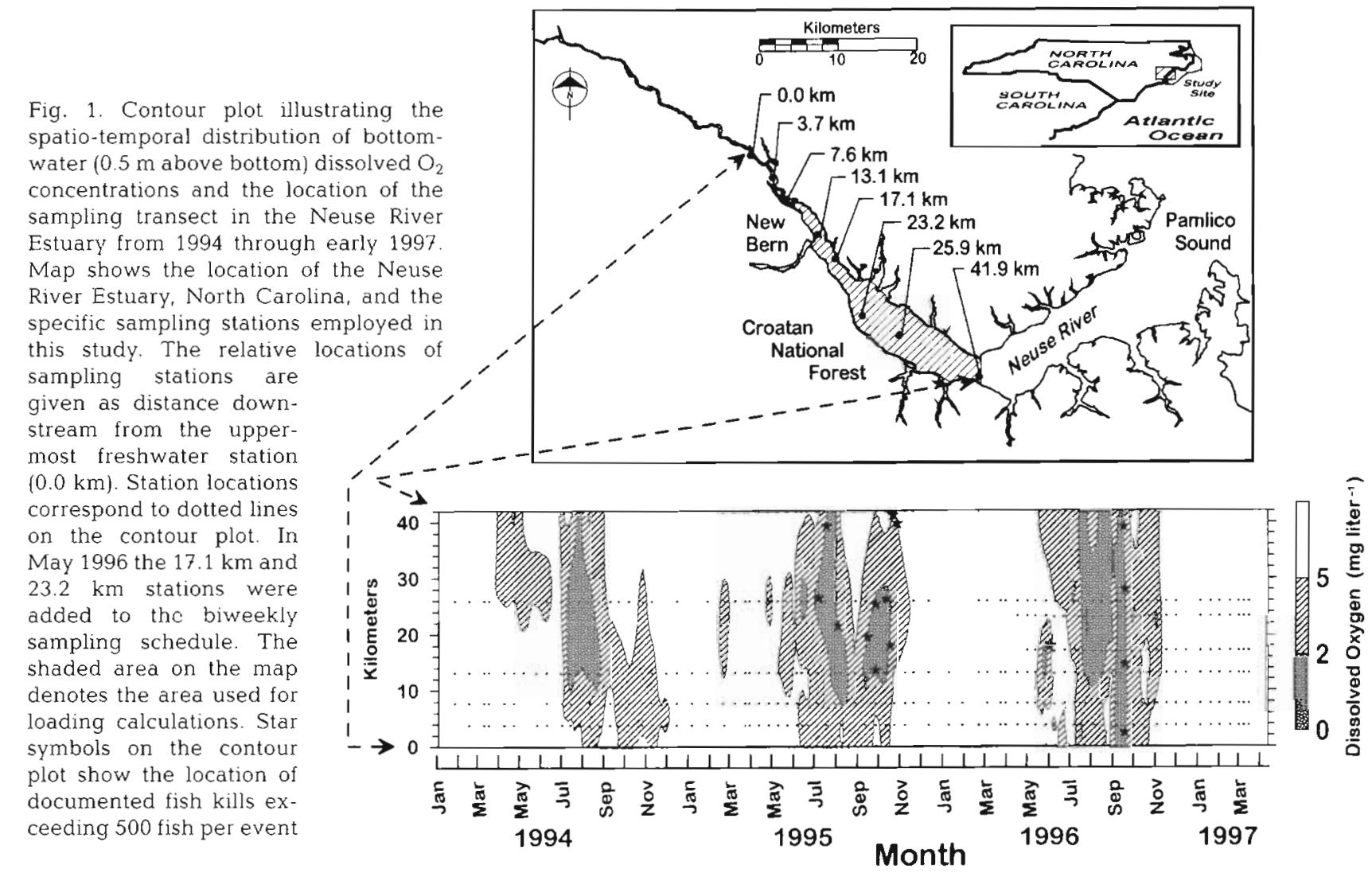

phere to remove abiotically precipitated ${ }^{14} \mathrm{C}$, and air dried, and incorporated ${ }^{14} \mathrm{C}$ was quantified by liquid scintillation counting, using a Beckman TD-5000 microprocessor-controlled liquid scintillation spectrometer. Primary productivity was computed using the formula of Wetzel \& Likens (1991). Dissolved inorganic carbon (DIC) content of water samples was determined by infrared absorbance, using a Beckman 865 infrared analyzer calibrated with sodium carbonate standards (Paerl 1987).

Phytoplankton biomass was estimated by spectrophotometric determinations of chl a, using the trichromatic technique (Strickland \& Parsons 1971). Chl a was extracted from Whatman GF/F-filtered $(47 \mathrm{~mm})$ estuarine water samples with $90 \%$ acetone. Extracts were analyzed using a Shimadzu model UV160 U spectrophotometer.

Inorganic $\mathrm{N}$ and $\mathrm{P}$ nutrient concentrations were determined on all water samples collected using a high sensitivity autoanalyzer (Lachat Quick Chem. IV; Lachat Instruments, Milwaukee, WI, USA). The following methods were employed: ammonium $=31-107-06-$ $1-A_{;}$nitrate $/$nitrite $=31-107-04-1-C_{i}$ phosphate $=31$ 115-01-3-A. Silicate analyses conducted throughout our sampling transect over the past 2 decades have indicated consistently high concentrations in the main stem of the estuary ( 40 to $150 \mu \mathrm{M} \mathrm{SiO}{ }_{2}$ Si:DIN ratios ranging from $4: 1$ to over 10:1) and no seasonal Si pattern in relation to diatom biomass [Harned \& Davenport 1990; U.S. Geological Survey (USGS), Raleigh, $\mathrm{NC}$. Previous nutrient addition bioassays in which Si (as $\mathrm{SiO}_{2}$ ) was added over a range of concentrations (alone and in combination with $\mathrm{N}$ and $\mathrm{P}$ ) indicated no $\mathrm{Si}$ stimulation of natural phytoplankton community productivity or biomass, while $\mathrm{N}$ stimulation was observed on a year-round basis (Paerl 1983, 1987. Paerl et al, 1990a, b). Both assessments indicated Si sufficiency throughout the year; accordingly, we did not routinely monitor this nutrient.

Particulate organic carbon (POC) was determined by CHN analysis (Perkin Elmer model 2400 series II CHN analyzer) of water samples filtered on precombusted $\left(500^{\circ} \mathrm{C}\right) 25 \mathrm{~mm}$ diameter $\mathrm{GF} / \mathrm{F}$ filters. Dissolved organic carbon (DOC) was analyzed on filtrates from samples filtered through precombusted GF/F filters. DOC measurements were made using high temperature combustion techniques on a Shimadzu model TOC-5000, equipped with an ASI-5000A autosampler (Benner \& Strom 1993). Acidified (HCl) samples were sparged for 8 min with $\mathrm{N}_{2}$ to drive off DIC. Background checks revealed complete removal of DIC by this treatment. Values represented the average of 3 injections. 
OM loading was calculated from biweekly measurements of phytoplankton primary productivity, POC and DOC at the sampling locations indicated in Fig. 1. Because of highly colored and turbid waters, primary productivity in this estuary is dominated (>90\%) by planktonic (as opposed to benthic) phototrophs (Boyer et al. 1993, Paerl et al. 1995). The OM loading attributable to planktonic productivity was calculated by multiplying primary productivity and water volume $\left(\mathrm{m}^{3}\right)$ for 6 representative segments of the estuary and integrating the value over the length of the study area. Productivity calculations assumed constant, homogeneous photosynthetic rates $\left(P_{\max }\right)$ for $9 \mathrm{~h} \mathrm{~d}^{-1}$ throughout the water column (mean depth $=2.18 \mathrm{~m}$ ). Daily phytoplankton productivity was estimated by linear interpolation of biweekly incubations within the 6 estuary segments. Water volumes were determined using digital area and depth (at mean low water) measurements provided by the National Ocean Survey (NOS; National Oceanographic and Atmospheric Administration). The total water surface area for the combined 6 segments was $122.4 \times 10^{6} \mathrm{~m}^{2}$ and the total volume was $267.4 \times 10^{6} \mathrm{~m}^{3}$.

External OM loadings were calculated by multiplying average daily river discharge (recorded at the Neuse River at Kinston, NC; USGS Station No. 02089500) and biweekly POC and DOC concentrations. Values for POC and DOC between sampling dates were estimated by linear interpolation. Documentation of the location and times of major fish kills in the Neuse Estuary during 1994-1996 was provided by the North Carolina Department of Environment, Health and Natural Resources, Division of Water Quality, Raleigh, NC (Fig. 1).
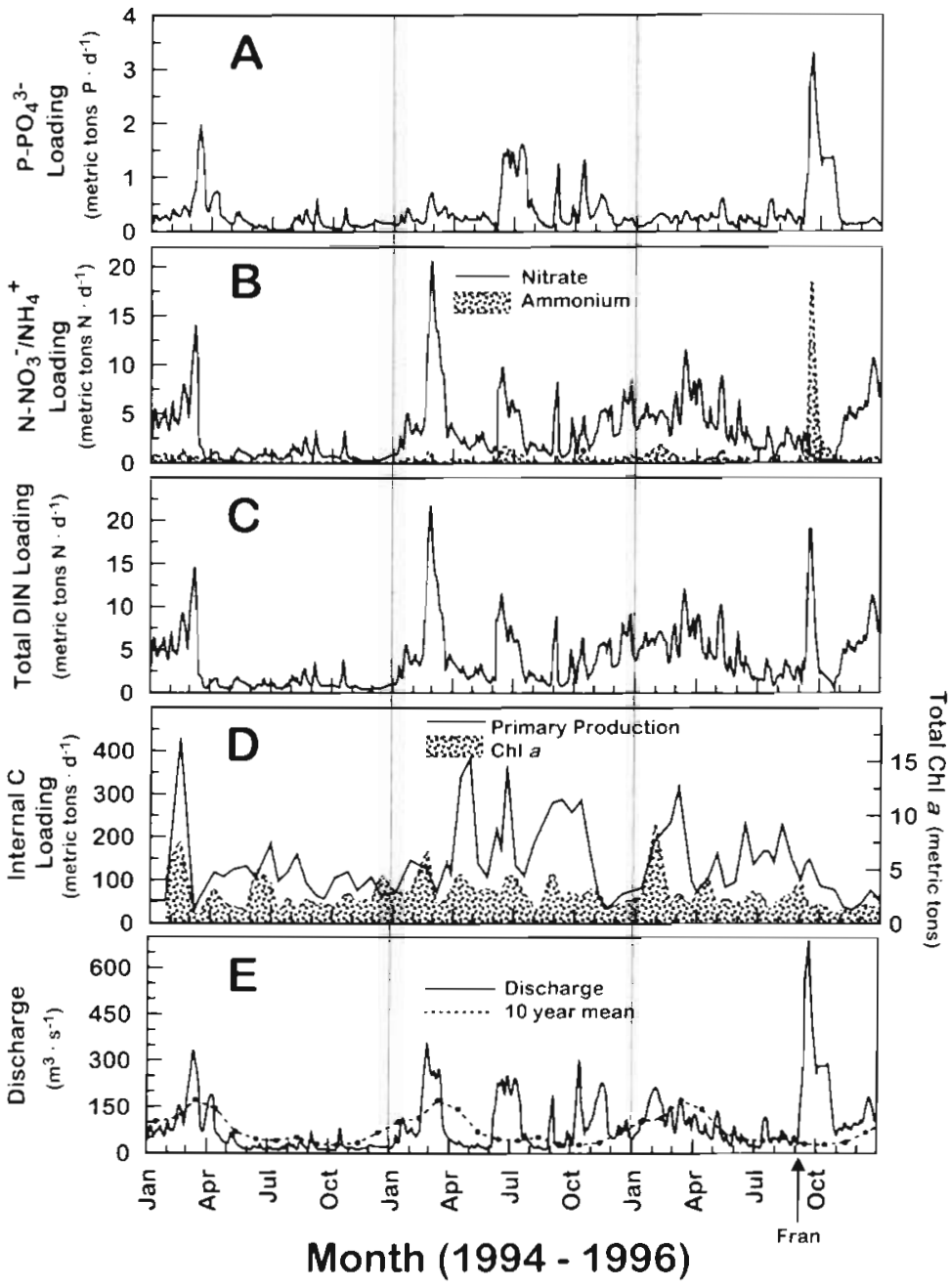

Fig. 2. Time series plots during 1994-1996 showing inorganic nutrient loading. (A) $\mathrm{PO}_{4}{ }^{3-}$. (B) $\mathrm{NO}_{3}^{-}\left(\mathrm{NO}_{3}{ }^{-}+\mathrm{NO}_{2}{ }^{-}\right)$and $\mathrm{NH}_{4}{ }^{+}$(C) Total DIN $\left(\mathrm{NO}_{3}{ }^{-}+\mathrm{NH}_{4}^{+}\right)$. (D) Internal C loading, as depth-integrated primary production for the sampling area. (E).Freshwater discharge for the Neuse River (Kinston gauging station; the $10 \mathrm{yr}$ monthly mean for discharge at this location is also shown). The time of Hurricane Fran's passage over the Neuse River watershed (5 September 1996) is also indicated

\section{RESULTS AND DISCUSSION}

\section{Spatial and temporal patterns of nutrient inputs and primary productivity}

The Neuse River Estuary exhibited distinct patterns of DIN and DIP in relation to freshwater discharge (Fig. 2). Pulses of externally derived DIN loading, dominated by $\mathrm{NO}_{3}{ }^{-}$, were closely associated with rainfalldriven runoff events, which were most common from late winter through spring. DIP (as $\mathrm{PO}_{4}{ }^{3-}$ ) loading was also controlled by runoff, but to a lesser extent than DIN. A large amount ( 60 to $80 \%$ ) of the annual phosphorus loading to the estuary has been attributed to sediment release during summertime periods of hypoxia and anoxia (Paerl 1987. Christian et al. 1991, Paerl et al. 1995); these releases were particularly prominent in 1995 and 1996, when hypoxic and anoxic events were most numerous and extensive (Figs. $1 \& 2$ ). Patterns of ammonium $\left(\mathrm{NH}_{4}{ }^{+}\right)$loading closely followed those observed for $\mathrm{PO}_{4}{ }^{3-}$, indicating similar sources, most likely the sediments, during periods of hypoxia and anoxia. A scatter plot of $\mathrm{PO}_{4}{ }^{3-}$ vs $\mathrm{NH}_{4}{ }^{+}$and $\mathrm{N}$ $\left(\mathrm{NO}_{3}{ }^{-}+\mathrm{NO}_{2}{ }^{-}\right)$loading determinations during $1994-$ 1996 confirms the close spatiotemporal relationship between $\mathrm{PO}_{4}{ }^{3-}$ and $\mathrm{NH}_{4}{ }^{+}$loading (Fig. 3). Primary productivity peaks closely followed periods of elevated $\mathrm{N}$-enriched spring and summer freshwater discharge 


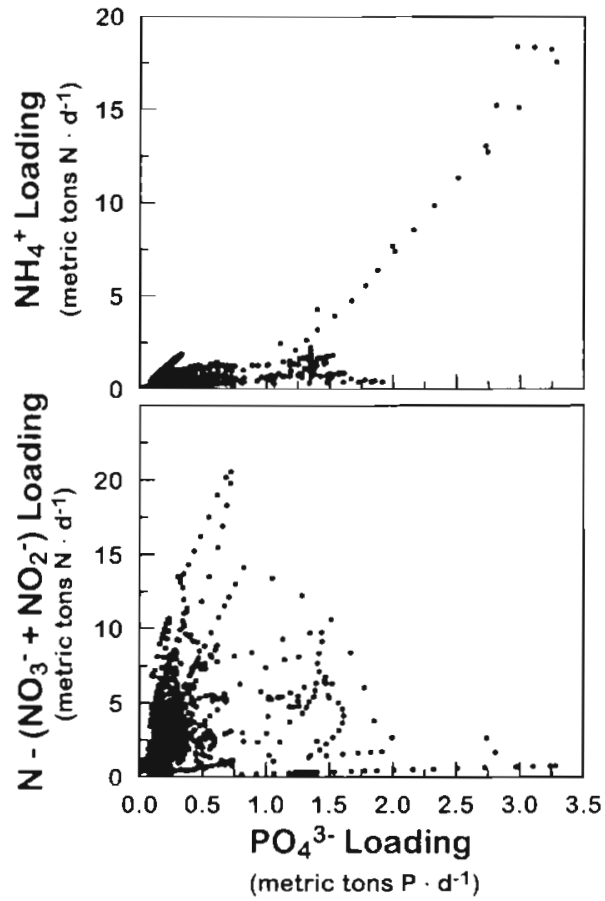

Fig. 3. Scatterplots showing the relationship between phosphate $\left(\mathrm{PO}_{4}{ }^{3-}\right)$ and ammonium $\left(\mathrm{NH}_{4}{ }^{+}\right)$and nitrate + nitrite $\left(\mathrm{NO}_{3}{ }^{-}+\mathrm{NO}_{2}\right)$ loadings determined for the Neuse River Estuary during 1994-1996

(Fig. 2). When discharge events were followed by relatively dry, low discharge periods and increased water retention time, blooms were often most pronounced. This sequence of events was evident during spring and summer of 1995 and spring 1996 (Fig. 2). When freshwater discharge was extremely high and accompanied by sustained flushing (e.g. discharge associated with the passage of Hurricane Fran in September 1996), no clear relationship between $\mathrm{N}$ or $\mathrm{P}$ loading and either primary productivity or phytoplankton biomass (chl a) was evident.

Previous nutrient addition bioassays (Paerl 1987. Rudek et al. 1991, Paerl et al. 1995) and nutrient uptake kinetic studies (Boyer et al. 1994) have shown $\mathrm{N}$ limited conditions throughout this estuary. Parallel, independent bioassay studies conducted during this study period likewise showed $\mathrm{N}$ limitation (Paerl et al. 1995, Pinckney et al. 1997), with $N$ enrichment achieving similar phytoplankton growth yields as $\mathrm{N}+\mathrm{P}$. In concert, past and present studies indicate that this eutrophic estuary has been $N$ limited throughout the 1980 s and 1990s. It is therefore not surprising that when hydrodynamic and nutritional conditions are favorable (i.e. elevated spring $N$ discharge followed by relatively low summer discharge and long water residence times), phytoplankton blooms are most commonly observed in this estuary (Christian et al. 1986 Paerl et al. 1995).

\section{Interannual hydrological and biogeochemical variability}

While biweekly sampling along the transect revealed spatiotemporal linkages between $\mathrm{N}$ loading, primary productivity, phytoplankton blooms, bottom water hypoxia and anoxia, and reported fish kills, considerable interannual variability in the sequences and magnitudes of these events was observed (Figs. $1 \& 2$ ). Linkages were closely related to the interactions of specific nutrient discharge and hydrologic flushing events (Fig. 2). There were large interannual differences in spring-summer runoff and flushing (i.e. wet vs dry years) accompanied by similarly varying patterns of DIN, DIP, particulate C, and OM (as C) loading as well as salinity stratification (Figs. $2 \& 4$ ). The propensity for the estuary to exhibit salinity gradients was a product of freshwater discharge; salinity gradients, measured as the difference between surface and bottom salinities, were negatively correlated with oxygen concentration in bottom waters (Spearman rank correlation, $\rho=-0.55, p<0.001$ ) (Fig. 4). Differing interannual hydrologic discharge patterns translated into contrasting scenarios of internally derived bloom dynamics, externally derived OM loading events, salinity stratification, hypoxia and anoxia (Fig. 4).

Based on a $10 \mathrm{yr}$ monthly mean discharge record, 1994 proved to be very close to an average hydrological year, with maximum rainfall and nutrient-rich riverine discharge largely confined to early spring, followed by relatively dry, low discharge summer months (Figs. 2 \& 4). This sequence of events favored the development of a spring phytoplankton bloom in 1994 (Fig. 2; Paerl et al. 1995), which was followed by a single period (July through mid-August) of mid-summer salinity stratification (shown as a vertical salinity gradient), hypoxia and anoxia extending from the 17.1 to $41.9 \mathrm{~km}$ river segments (Figs. 1 \& 4). A few small fish kills ( $<500$ fish killed per event) occurred in this region during the hypoxic period.

In contrast to the relatively dry summer conditions of 1994, several large rainfall events and elevated runoff occurred in spring and summer of 1995 (Figs. 2 \& 4), supporting multiple phytoplankton blooms that persisted throughout summer and fall months (Fig. 2). These blooms preceded extensive hypoxia and anoxia in salinity-stratified segments of the estuary from early July until October (Figs. 1 \& 4). While rainfall was abundant during the summer of 1995, discharge and flushing associated with runoff was not high enough to destratify vertical salinity gradients and flush phytoplankton bloom populations out of the estuary (Figs. 2 \& 4). The result of large pulses of nutrient input associated with elevated runoff was a series of bloom events overlying the salt wedge, which effectively 'trapped' 


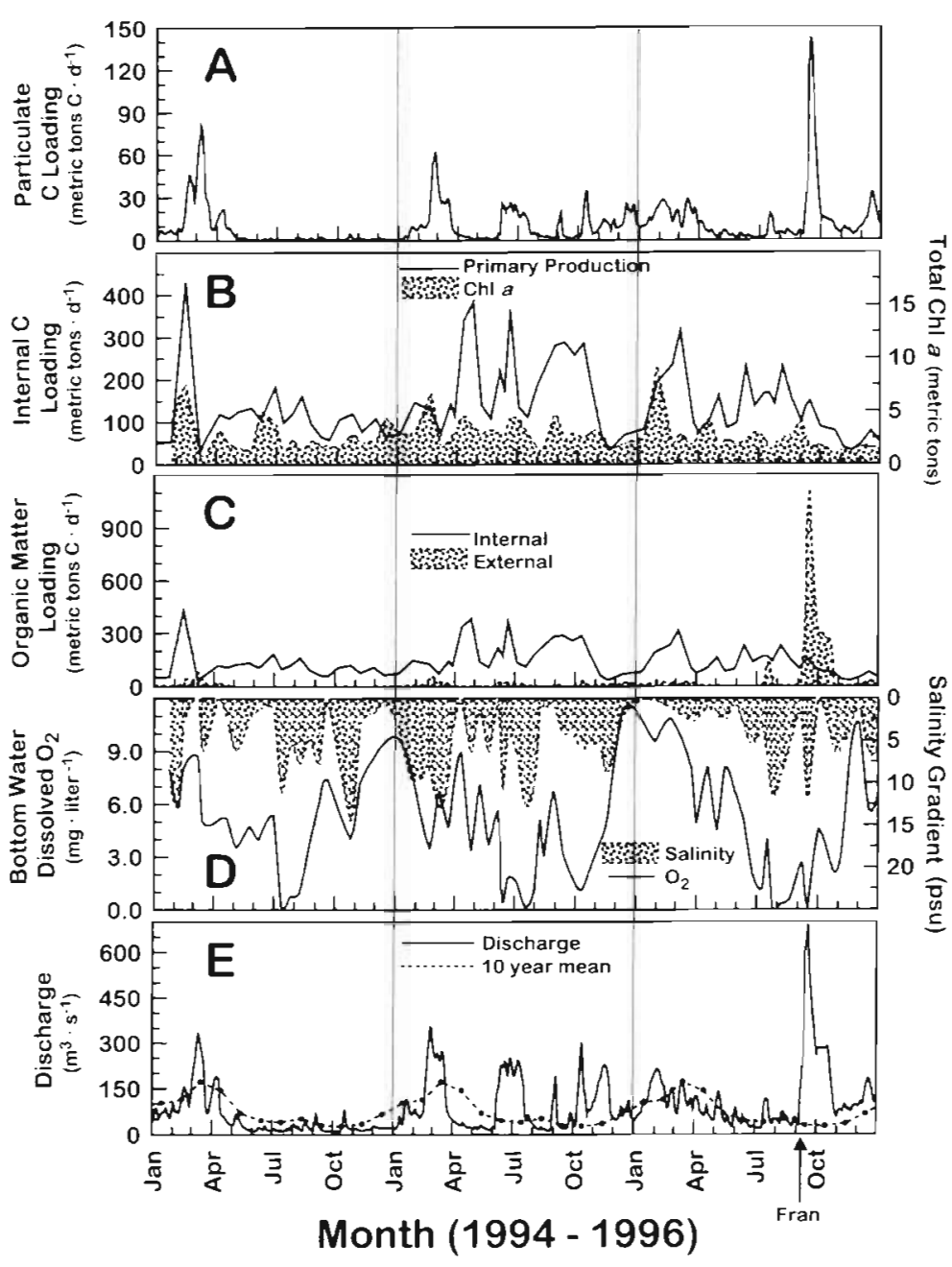

Fig. 4. Time series plots showing various sources and forms of organic matter loading, periods of hypoxia and anoxia and freshwater discharge for the Neuse Rjver Estuary during 1994-1996. (A) Particulate carbon loading. (B) Internal carbon loading, based on measurements of primary production, as well as chl a, integrated over the sampling area. (C) A comparison of internally generated (primary production) vs externally supplied OM loading. Note that externally supplied OM loading includes both particulate and dissolved organic C. (D) Bottom-water dissolved $\mathrm{O}_{2}$ concentrations and corresponding vertical salinity gradient at the midestuarine $25.9 \mathrm{~km}$ sampling location (see Fig. 1 for location). (E) Freshwater discharge at the Kinston gauging station; the 10 yr monthly mean for discharge at this location is also shown. The time of Hurricane Fran's passage over the Neuse watershed (5 September 1996) is also indicated

runoff supporting moderate productivity and bloom events. The ensuing few months (May-July) exhibited some hypoxia, but remained relatively free of major anoxia events, reflecting the preceding period of moderate phytoplankton production (Figs. 1 \& 4). This scenario was radically altered later in the summer, when the Neuse River basin was impacted by 2 summer hurricanes: Bertha (12 July, category 3) and Fran (5 September, category 4). Bertha made landfall near Jacksonville, NC (approximately $40 \mathrm{~km}$ southeast of the study area) and proceeded in a northerly direction, largely affecting the downstream lower Neuse River watershed and adjacent Pamlico Sound. Winds were in excess of $140 \mathrm{~km} \mathrm{~h}^{-1}$, causing complete water column mixing and large storm surges $(3.5 \mathrm{~m})$ in the estuary. Bertha delivered little rainfall to the upper watershed ( 1.5 to $3 \mathrm{~cm}$ ) however, which was reflected in relatively low water discharge to the estuary (Figs. $2 \& 4$ ). Fran was a much larger (size-and strengthwise) storm system which made landfall near Wilmington, NC, approximately $90 \mathrm{~km}$ south of the Neuse River watershed. Its northwesterly path directly crossed the entire Neuse River basin, inundating it in places with $>28 \mathrm{~cm}$ of rainfall over an $18 \mathrm{~h}$ period.

The massive runoff and flushing following Hurricane Fran resulted in a very large, nutrient- and OM-enriched, $\mathrm{O}_{2}$-depleted, highly turbid freshet dominating the estuary (Figs. 2 \& 4). This caused destratification of the salt wedge and flushed the resident phytoplankton community out of the study area, greatly reducing primary production and chl a concentrations (Figs. $2 \& 4$ ). The OM load accompanying the freshet $(>14 \times$ $10^{6} \mathrm{~kg} \mathrm{C)}$ promoted extensive hypoxia/ anoxia and fish/shellfish mortality throughout the $42 \mathrm{~km}$ long study area (Figs. 1 \& 4). In contrast to 1994 and 1995, this extensive anoxic event was caused by external watershed-based OM loading rather than nutri-

the organic matter produced by the blooms, followed by extensive bottom water hypoxia and anoxia (Figs. 1 , 2 \& 4). Numerous large fish kills (in excess of 50000 fish) were observed in the 17.1 to $41.9 \mathrm{~km}$ river segment exhibiting persistent hypoxic and anoxic conditions (Figs. 1 \& 4). Hypoxia, anoxia and fish kills ceased with increased discharge, destratification and cooler water temperatures in late fall (November 1995).

The winter and spring of 1996 exhibited near-mean hydrological conditions (Fig. 2), with a period of spring ent-driven internal bloom events. Rapid and persistent flushing associated with Fran's discharge led to relatively low internal $C$ loading led to reduced primary production in 1996 (76\% of 1995) and large blooms did not develop in the sampling area (Figs. 2 \& 4).

Throughout the study period, reported fish kills appeared to reflect the magnitudes, aerial coverage and duration of hypoxia and anoxia events, with only minor kills being reported in 1994, at least 8 large fish 
kills associated with the extensive mid-summer hypoxic/anoxic period in 1995, and major fish kills in 1996 occurring during anoxia following the passage of Hurricane Fran (Fig. 1).

\section{Organic matter loading in relation to hypoxia and anoxia potentials}

Based on the dimensions of the estuary's 6 segments and $N$ and $O M$ input data, the estimated annual $N$ and OM loadings were calculated for 1994, 1995, and 1996. Annual external DIN plus particulate $N$ loadings were $1.141,2.077$ and $2.435\left(\times 10^{6} \mathrm{~kg} \mathrm{~N}\right)$ for 1994,1995 and 1996, respectively. External sources of OM were 2.680 , 4.079 , and 26.211 ( $\times 10^{6} \mathrm{~kg} \mathrm{C}$ ), respectively. Internal OM annual loadings were $42.748,62.908$, and 48.010 $\left(\times 10^{6} \mathrm{~kg} \mathrm{C}\right.$ ), respectively.

Interannual variability enabled the assessment of hypoxia/anoxia potentials from nutrient-driven causes (i.e. N-enhanced phytoplankton blooms during dry to moderately wet years; 1994-1995) versus episodic pulses of watershed-derived external OM loading following the high rainfall, river discharge, and flushing associated with Hurricane Fran in September 1996 (Figs. 2 \& 4). Each year was distinguished by dramatic differences in OM loading dynamics associated with river discharge (Fig. 4) In a mean discharge year (1994), runoff and $\mathrm{N}$ loading were confined to the late winter through early spring wet period, followed by a spring phytoplankton bloom and a single summer hypoxia/anoxia period (Figs. 2 \& 4). More than $50 \%$ of the annual primary production was attributable to spring blooms in mean discharge years and the summer hypoxia/anoxia event reflected sediment/bottomwater $\mathrm{O}_{2}$ consumption associated with it (Paerl et al. 1995). The 1995 spring-summer period yielded higher than average discharge and elevated DIN loading, dominated by $\mathrm{NO}_{3}^{-}$(Fig. 2). In conjunction with this elevated DIN load, total annual primary production in 1995 was $47 \%$ higher than in 1994 . Several large summer rainfall and discharge events were responsible for the elevated DIN loads (Fig. 2), which in turn fueled 2 large summer-fall blooms, each of which contributed from 7 to $>12 \times 10^{6} \mathrm{~kg} \mathrm{C}$ to the salinity-stratified estuary (Fig. 4). These large increases in primary production translated into corresponding bimodal peaks of bottom-water hypoxia and anoxia which closely followed (in time and space) the blooms (Figs. 1 \& 4). The resultant expansion of $\mathrm{O}_{2}$ depletion in 1995 (vs 1994) spatially and temporally coincided with large fish kills throughout bloom-impacted segments of the study area (Fig. 1)

The causal mechanisms for hypoxia/anoxia in 1994, 1995 and 1996 differed dramatically. During 1994 and
1995, nutrient ( $N$ ) enhanced phytoplankton blooms were the main sources of $\mathrm{OM}$ triggering $\mathrm{O}_{2}$ depletion in salinity-stratified bottom waters. In this scenario, internal OM production as phytoplankton biomass was hypothesized to be controlled closely by external nutrient loading and, as evidenced by low discharge, relatively long water residence times, favorable for bloom formation (Christian et al. 1986, Paerl 1988, Paerl et al. 1995). During 1996, internal OM production and phytoplankton blooms were restricted by high flushing rates (water residence times $<30 \mathrm{~d}$ ), while a bulk of the OM driving $\mathrm{O}_{2}$ consumption was derived from external watershed-based sources. The OM loading for the summer of 1996 was estimated to be $75 \%$ derived from the watershed and $25 \%$ derived from phytoplanktondominated primary production. In 1994 and 1995, the relative OM contributions from these sources were reversed at approximately the same ratio.

Time scales of OM loading versus hypoxia/anoxia, and subsequent fish mortality differed between 1995 and 1996, the 2 years exhibiting significant kills. The sequence of events linking pulses of $\mathrm{N}$ loading to phytoplankton blooms, hypoxia, and fish kills in summer 1995 occurred over weeks to several months. In 1996, the large pulse of OM-laden, $\mathrm{O}_{2}$-consuming runoff resulting from the passage of Hurricane Fran induced fish kills within $2 \mathrm{~d}$. Hydrodynamic conditions contrasted sharply between these years. In relatively low flow, long residence time 1995, phytoplanktonbloom-associated OM was trapped and consumed below the pycnocline, producing bottom-water hypoxia/ anoxia. In 1996, the sudden, large OM enrichment associated with runoff from Hurricane Fran induced hypoxia/anoxia throughout the water column. In both cases, massive fish kills resulted.

We estimated a minimal level of OM loading required for oxygen depletion to become established for this estuary. Quantitative comparisons of externally supplied runoff and internally generated phytoplankton blooms as sources of OM responsible for localized $\mathrm{O}_{2}$ depletion and fish kills indicate a striking similarity of ecosystem response per amount of OM supplied (from respective sources) to regions of potential hypoxia/anoxia. From this, a threshold of OM loading was formulated for the Neuse River Estuary. We estimate that if $8 \times 10^{6} \mathrm{~kg} \mathrm{C}$ input per event from either external or internal sources is exceeded, the potential for sizeable fish kills is reached. We caution that there is a large amount of variability in this estimate, based on interacting meteorological, hydrodynamic, and anthropogenic forcing features. System response to nutrient inputs is regulated in part by meteorological conditions. For example, specific meteorological events, such as strong winds associated with frontal passages, can effectively mix the shallow water col- 
umn $(<5 \mathrm{~m})$, dispersing sediment-regenerated nutrients and re-oxygenating previously $\mathrm{O}_{2}$ depleted waters close to saturation levels within a few hours.

\section{Implications for nutrient management of water quality}

Close scrutiny of the spatial and temporal relationships between hydrology and nutrient (specifically $N$ ) and $O M$ loading in the Neuse River basin over a 3 yr period (1994-1996) reveals a complex but predictable interplay of the timing, magnitude, and delivery of inorganic and organic nutrients, translation into primary production, $\mathrm{O}_{2}$ consumption, hypoxia/anoxia, and resultant fish and shellfish mortality. Dramatic differences in causes and mechanisms underlying hypoxia/anoxia dynamics and fish kills can be expected for this regionally representative (i.e. Albemarle-Pamlico Sound system) shallow estuary.

In average to dry hydrological years, where high winter-spring runoff and nutrient loading precede a lower flow (relatively high retention time) period of maximum phytoplankton production and high bloom potential, nutrient (specifically $\mathrm{N}$ ) input constraints are clearly the most feasible, effective water quality control option. Watershed $\mathrm{N}$-loading trends over the past 2 decades and experimental evidence (Paerl \& Bowles 1987. Stanley 1988, Harned \& Davenport 1990, Dodd et al. 1993) suggest at least a $30 \%$ annual cutback on $N$ inputs accompanied by a nutrient cap restricting maximum annual $\mathrm{N}$ inputs to current levels will be needed to achieve perceptible improvements in water quality, including long-term reductions in phytoplankton blooms and associated hypoxia/anoxia (North Carolina State Senate 1996). While such nutrient management strategies may yield improvements in water quality for mean hydrological years (e.g. 1994), they will, in all likelihood, not entirely eliminate periodic fish kills in this and similar salinity-stratified estuaries. During high runoff years, such as 1995, larger cutbacks in $N$ input may be needed to obtain any measurable reductions in hypoxia/anoxia potentials. Hurricane or tropical summer storm-impacted years, such as 1996, will experience large freshets accompanied by uncontrollable external loading (i.e. flushing) of OM that overwhelm any nutrient-based strategies for reducing hypoxia.

A long-term water quality management strategy for watershed-dominated estuarine systems such as the Neuse River Estuary must therefore incorporate assessments of the probability that events beyond the control of land-based nutrient management will determine the spatial and temporal extent of hypoxia/ anoxia and resultant faunal mortality. This strategy must be able to estimate and articulate the background or natural frequencies, magnitudes, and areal coverage of $\mathrm{O}_{2}$ depletion events. Without taking hydrological extremes such as those observed during this study into consideration, a realistic, effective and publically acceptable management strategy aimed at long-term improvement of water quality is unlikely to emerge.

Acknowledgements. We thank $M$. Alpern for use of TOC equipment, P. Wyrick, T Nanni, M. Go, S. Thompson, M. Piehler, C. Donahue, M. Fitzpatrick, D. Whitall, P. Moisander, and $\mathrm{K}$. Howe for assistance with field measurements and sample analyses and M. Lebo, K. Reckhow, R. Christian, D. Stanley, R. Leuttich and J. Bales for helpful discussions and review of this work. Fish kill data were supplied by the North Carolina Department of Environment, Health and Natural Resources, Division Water Quality and river discharge data were provided by the USGS/Raleigh. This work was supported by the U.S. Dept of Agriculture (Project 93-371029103), NC Sea Grant Program (R/MER 37), UNC Water Resources Research Institute (Project 70166) and the National Science Foundation (Project DEB 9210495). We appreciate the thoughtful and constructive critiques and comments provided by several anonymous reviewers

\section{LITERATURE CITED}

Ambio (1990) Marine eutrophication. Ambio 19:101-176

American Rivers Foundation (1997) Report on the 20 most threatened American rivers. American Rivers Foundation, New York

Benner R, Strom M (1993) A critical evaluation of the analytical blank associated with DOC measurements by hightemperature catalytic oxidation. Mar Chem 41:153-160

Boyer JN, Christian RR, Stanley DW (1993) Patterns of phytoplankton primary productivity in the Neuse River Estuary. Mar Ecol Prog Ser 97:287-297

Boyer JN, Stanley DW, Christian RR (1994) Dynamics of $\mathrm{NH}_{4}^{*}$ and $\mathrm{NO}_{3}{ }^{-}$uptake in the water column of the Neuse River estuary, North Carolina. Estuaries 17:361-371

Christian RR, Boyer JN, Stanley DW (1991) Multi-year distribution patterns of nutrients within the Neuse River Estuary. Mar Ecol Prog Ser 71:259-274

Christian RR, Bryant W, Stanley DW (1986) The relationship between river flow and Microcystis aeruginosa blooms in the Neuse River, North Carolina. Rep. No. 223, Univ North Carolina Water Resources Res Inst, Raleigh

Cloern JE (1996) Phytoplankton bloom dynamics in coastal ecosystems: a review with some general lessons from sustained investigations of San Francisco Bay, California. Rev Geophys 34:127-168

Cooper S, Brush G (1991) Long-term history of Chesapeake Bay anoxia. Science 254:992-996

Copeland BJ, Hart K (1995) Proceeding of NC Nutrient Summit. North Carolina Sea Grant Program, Raleigh

De Jonge VN, Boynton W, D'Elia CF, Elmgren R, Welsh BL (1994) Responses to developments in eutrophication in four different North Atlantic estuarine systems. In: Dyer $\mathrm{KR}$, Orth RJ (eds) Changes in fluxes in estuaries: implications from science to management. Olsen \& Olsen. Fredensborg, p 179-196

D'Elia CF, Sanders JG, Boynton WR (1986) Nutrient enrichment studies in a coastal plain estuary: phytoplankton growth in large scale, continuous cultures. Can J Fish Aquat Sci 43:397-406 
Dodd RC, Cunningham PA, Curry RJ, Stichter SJ (1993) Watershed planning in the Albemarle-Pamlico Estuarine System. Report No. 93-01, Research Triangle Institute, Research Triangle Park, NC. North Carolina Dept of Environment, Health and Natural Resources

Dyer KR, Orth RJ (eds) (1994) Changes in fluxes in estuaries: implications from science to management. Olsen \& Olsen, Fredensborg

Elmgren R (1989) Man's impact on the Baltic Sea: energy flows today and at the turn of the century. Ambio 18: 326-332

Fisher TR, Peele ER, Ammerman JW, Harding LW (1992) Nutrient limitation of phytoplankton in Chesapeake Bay. Mar Ecol Prog Ser 82:51-63

Geyer WR (1988) The advance of a salt wedge: observations and dynamical model. In: Donkers J, van Leussen W (eds) Physical processes in estuaries. Springer-Verlag, Berlin, p 181-195

Granéli E, Wallstrom K, Larsson U, Granéli W, Elmgren R (1990) Nutrient limitation of primary production in the Baltic Sea. Ambio 19:142-151

Harned DA, Davenport MS (1990) Water-quality trends and basin activities and characteristics for the Albemarle-Pamlico Estuarine System, NC and VA. Report 90-398, US Geological Survey, Raleigh

Hobbie JE, Smith NW (1975) Nutrients in the Neuse River Estuary, NC. Report No. UNC-SG-75-21, UNC Sea Grant Program, North Carolina State Univ, Raleigh

Justic D, Rabalais NN, Turner RE (1996) Effects of climate change on hypoxia in coastal waters: a doubled $\mathrm{CO}_{2}$ scenario for the northern Gulf of Mexico. Limnol Oceanogr 41:992-1003

Kennedy VS (1986) The estuary as a filter Academic Press, New York

Mallin MA, Paerl HW (1992) Effects of variable irradiance on phytoplankton productivity in shallow estuaries. Limnol Oceanogr 37:54-62

Malone TC, Crocker LH, Pike SE, Wendler BW (1988) Influences of river flow on the dynamics of phytoplankton production in a partially stratified estuary. Mar Ecol Prog Ser 48:235-249

Neilson BJ, Cronin LE (eds) (1981) Estuaries and nutrients. Humana Press, Clifton, NJ

Nixon SW (1986) Nutrient dynamics and the productivity of marine coastal waters. In: Clayton D, Behbehani $M$ (eds) Coastal eutrophication. The Alden Press, Oxford, p 97-115

Nixon SW (1995) Coastal marine eutrophication: a definition, social causes, and future concerns. Ophelia 41:199-220

North Carolina State Senate (1996) Senate Select Committee on Water Quality and Fish Kills, Summary Report, May 1996. North Carolina State Senate, Raleigh

Paerl HW (1983) Factors regulating nuisance blue-green algal bloom potentials in the lower Neuse River. Report No. 177, UNC Water Resourc Res Inst, Raleigh

Paerl HW (1987) Dynamics of blue-green algal (Microcystis aeruginosa) blooms in the lower Neuse River, NC: causative factors and potential controls. Report No. 229, UNC Water Resourc Res Inst, Raleigh

Paerl HW (1988) Nuisance phytoplankton blooms in coastal,

Editorial responsibility: Gordon Thayer (Contributing Editor), Beaufort, North Carolina, USA estuarine, and inland waters. Limnol Oceanogr 33 $823-847$

Paerl HW, Bowles ND (1987) Dilution bioassays: their application to assessments of nutrient limitation in hypereutrophic waters. Hydrobiologia 146:265-273

Paerl HW, Mallin MA, Donahue CA, Go M, Peierls BL (1995) Nitrogen loading sources and eutrophication of the Neuse River Estuary, NC: direct and indirect roles of atmospheric deposition. Rep No. 291, Univ North Carolina Water Resources Res lnst, Raleigh

Paerl HW, Mallin MA, Rudek J, Bates PW (1990a) The potential for eutrophication and nuisance algal blooms in the lower Neuse River, NC. Albemarle-Pamlico Estuarine Study Report 90-15. North Carolina Dept Nat Res \& Comm Develop, Raleigh

Paerl HW, Rudek J, Mallin MA (1990b) Stimulation of phytoplankton production in coastal waters by natural rainfall inputs: nutritional and trophic implications. Mar Biol 107 247-254

Parker CA, O'Reilly JE (1991) Oxygen depletion in Long Island Sound: a historical perspective. Estuaries 14 $248-265$

Pinckney JL, Millie DF, Vinyard BT, Paerl HW (1997) Environmental controls of phytoplankton bloom dynamics in the Neuse River Estuary (North Carolina, USA). Can J Fish Aquat Sci 54:2491-2501

Pritchard D (1955) Estuarine circulation processes. Proc Am Soc Civil Eng 81(177):1-11

Rudek J, Paerl HW, Mallin MA, Bates PW (1991) Seasonal and hydrological control of phytoplankton nutrient limitation in the lower Neuse River Estuary, North Carolina. Mar Ecol Prog Ser 75:133-142

Ryther JH, Dunstan WM (1971) Nitrogen, phosphorus, and eutrophication in the coastal marine environment. Science $171: 1008-1112$

Stanley DW (1988) Historical trends in nutrient loading to the Neuse River Estuary, NC. In: Lyke W, Hoban T (eds) Proc AWRA Symp on Coastal Water Resources. AWRA Tech Publ Ser TPS-88-1 American Water Resources Association, Bethesda, MD, p 155-164

Steele JH (1974) The structure of marine ecosystems. Harvard Univ Press, Cambridge

Strickland JDH, Parsons TR (1971) A practical handbook of seawater analysis. Bull Fish Res Bd Can 167

Tedder SW. Sauber J, Ausley J, Mitchell S (1980) Working paper: Neuse River investigation 1979. Div Environ Management, North Carolina Dept Nat Res \& Comm Develop Raleigh

Van Dolah PR, Anderson G (1991) Effects of Hurricane Hugo on salinity and dissolved oxygen conditions in the Charleston Harbor Estuary. J Coastal Res 8:83-94

Welsh BL, Eller FC (1991) Mechanisms controlling summertime oxygen depletion in western Long Island Sound. Estuaries 14:265-278

Wetzel RG, Likens GE (1991) Limnological analysis. WR Saunders, Philadelphia

Winn R, Knott D (1992) An evaluation of the survival of experimental populations exposed to hypoxia in the Savannah River Estuary. Mar Ecol Prog Ser 88:161-179

Submitted: August 15, 1997; Accepted: February 16, 1998

Proofs received from author(s): April 29, 1998 